\title{
A rare cause of excruciating chest pain mimicking acute coronary syndrome
}

\author{
L. Hobohm ${ }^{1}$ D. Krompiec ${ }^{1}$ R. Michel ${ }^{1}$ Y. Yang ${ }^{2}$ F. Schmidt ${ }^{1}$ C. Düber ${ }^{2}$ T. Münzel ${ }^{1}$ P. Wenzel ${ }^{1}$
}

Published online: 26 October 2016

(C) The Author(s) 2016. This article is available at SpringerLink with Open Access.

A 62 year-old male presented to the chest pain unit with chest pain and nausea, reporting that the symptoms occurred one hour after dinner. His medical history included a foudroyant event of pulmonary embolism with embolectomy in 2012.

Due to clinical deterioration and the history of pulmonary embolism, we decided to perform a contrast computed tomography angiography (CT). We could rule out aortic dissection and pulmonary embolism, However, CT revealed a mixed axial para-oesophageal upside-down stomach (UDS) compressing the left ventricle (Fig. 1).

UDS is the rarest type of hiatal hernia and can manifest clinically in a wide variety of symptoms as demonstrated in this case [1]. As causes of chest pain, gastrointestinal disease other than peptic ulcer or reflux-related diseases which might include UDS were reported to be below $1 \%$ [2]. In UDS patients, complications such as incarceration, volvulus development as well as acute gastric bleeding can lead to a life-threatening emergency with prevalence of $30.4 \%$ and can require immediate surgery $[3,4]$.
Fig. 1 Computed tomography (a) and gastrointestinal contrast series (b) show a mixed axial and para-oesophageal upside-down stomach (red arrow) compressing the left ventricle, without any incarcerated portions of the stomach
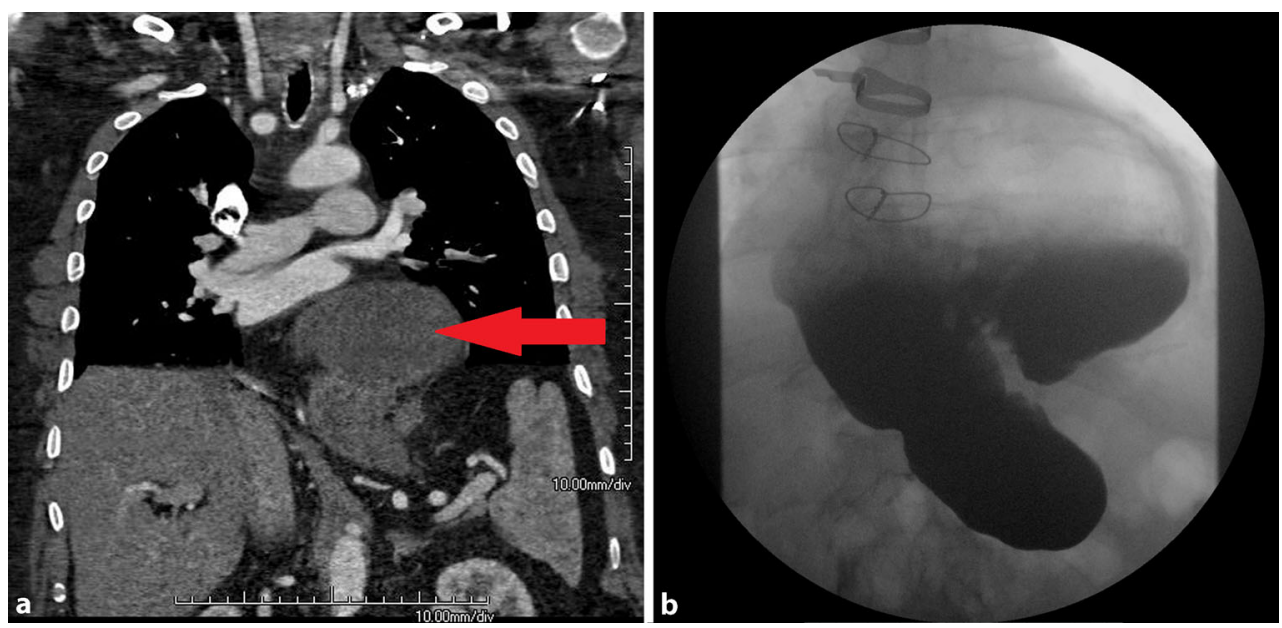

L. Hobohm

lukas.hobohm@unimedizin-mainz.de

1 Center of Cardiology, Cardiology I, Johannes Gutenberg

University Medical Center Mainz, Mainz, Germany

2 Department of Diagnostic and Interventional Radiology, Johannes Gutenberg University Medical Center Mainz, Mainz, Germany 
Conflict of interest L. Hobohm, D. Krompiec, R. Michel, Y. Yang, F. Schmidt, C. Düber, T. Münzel and P. Wenzel declare that they have no competing interest.

Open Access This article is distributed under the terms of the Creative Commons Attribution 4.0 International License (http:// creativecommons.org/licenses/by/4.0/), which permits unrestricted use, distribution, and reproduction in any medium, provided you give appropriate credit to the original author(s) and the source, provide a link to the Creative Commons license, and indicate if changes were made.

\section{References}

1. Hill LD, Tobias JA. Paraesophageal hernia. Arch Surg. 1968;96: 735-44.

2. Verdon F, Herzig L, Burnand B, et al. Chest pain in daily practice: occurrence, causes and management. Swiss Med Wkly. 2008;138:340-7.

3. Hill LD. Incarcerated paraesophageal hernia. A surgical emergency. Am J Surg. 1973;126:286-91.

4. Trainor D, Duffy M, Kennedy A, Glover P, Mullan B. Gastric perforation secondary to incarcerated hiatus hernia: an important differential in the diagnosis of central crushing chest pain. Emerg Med J. 2007;24:603-4. 